Goldschmidt 2021 Abstract

https://doi.org/10.7185/gold2021.6710

\section{Life in an uncertain world: how a characteristically dynamic environment forges a resilient microbiome and differential fates of soil carbon}

\author{
JENNIFER PETT-RIDGE ${ }^{1}$, ASHLEY CAMPBELL ${ }^{1}$, \\ RACHEL HESTRIN ${ }^{1}$, AMRITA BHATTACHARYYA ${ }^{2}$, \\ JEFFREY A KIMBREL ${ }^{1}$, GARY TRUBL ${ }^{1}$, VANESSA L \\ BRISSON $^{1}$, YANG LIN ${ }^{3}$, WHENDEE SILVER ${ }^{4}$, PETER K \\ WEBER $^{1}$, STEVEN J BLAZEWICZ ${ }^{1}$ AND PETER S NICO ${ }^{2}$ \\ ${ }^{1}$ Lawrence Livermore National Laboratory \\ ${ }^{2}$ Lawrence Berkeley National Laboratory \\ ${ }^{3}$ University of Florida \\ ${ }^{4}$ University of California, Berkeley \\ Presenting Author: pettridge2@1lnl.gov
}

Environmental fluctuations (both spatial and temporal) are a persistent reality in soil systems, and likely underpin the enormous phylogenetic and functional diversity of soil microbial communities. In upland systems, soil oxygen availability varies in time and space, but is rarely acknowledged as an important determinant, even though redox potential fundamentally regulates terrestrial biogeochemical cycling by limiting soil microbial metabolism and thus the fate of soil organic carbon. To query microbial communities adapted to frequent environmental oscillations, and their effects on the fate of soil carbon, we conducted a laboratory ${ }^{13} \mathrm{C}$ isotope tracer study with a wet tropical soil adapted to oscillating soil redox conditions. By following the decomposition of ${ }^{13} \mathrm{C}$-enriched plant litter, and tracing isotope enrichment into microbial and viral DNA, and multiple soils pools (soil metabolites, mineral-associated SOC, DOC, $\mathrm{CO}_{2}$ ) we targeted activities of the 'active' portion of the soil microbiome-a small subset $(\sim 8 \%)$ of the total soil community. While cumulative production of SOM-derived $\mathrm{CO}_{2}$ was highest in consistently oxic soils, cumulative $\mathrm{CO}_{2}$ production from added ${ }^{13} \mathrm{C}$-litter was not linked to oxygen availability, and indeed, initially highest under static anoxic conditions. The DOC pool was also largest under static anoxic conditions; it increased immediately following oxic-anoxic transitions and included distinct litter-derived decomposition products and microbial metabolites. Results from two-pool kinetic modeling showed that more frequent anoxic exposure limited decomposition of the slow-cycling $\mathrm{C}$ pool, but not the fast-cycling pool. At the microscale, NanoSIMS-STXM imaging showed that nearly all enriched ${ }^{13} \mathrm{C}$ litter underwent decomposition, but redox differentially affected functional group composition. Quantitative stable isotope probing indicates there were phylogenetically conserved trends in litter $\mathrm{C}$ assimilation, but overall, active taxa exhibited a surprising tolerance to all redox regimes, indicating that some organisms do not conform to strictly obligate aerobic or anaerobic lifestyles in this naturally dynamic system. Furthermore, many of the taxa that actively assimilated litter $\mathrm{C}$ were not abundant. These results highlights the potential contribution of 'rare' organisms to the terrestrial $\mathrm{C}$ cycle and suggest that shifting redox periodicity influences $\mathrm{C}$ cycling in tropical forest soils through its effects on microbial composition and activity. 